\title{
CONTROLE SOCIAL E LUTAS QUILOMBOLAS NO MARANHÃO: CRUZANDO SABERES PARA A GARANTIA DE DIREITOS TERRITORIAIS
}

\author{
SOCIAL CONTROL AND QUILOMBOLA STRUGGLES IN MARANHÃO: CROSSING \\ KNOWLEDGE FOR THE GUARANTEE OF TERRITORIAL RIGHTS
}

\section{Marivania Leonor Souza Furtado ${ }^{1}$ \\ http://lattes.cnpq.br/3275591203804166 \\ https://orcid.org/0000-0002-2140-304X}

Recebido em: 8 de junho de 2020.

Aprovado em: 11 de julho de 2020.

RESUMO: Esta pesquisa analisa a relação de produção de saberes construídos em processos formativos integrativos do mundo acadêmico ao universo das lutas quilombolas no Estado do Maranhão. Toma como metodologia privilegiada para tal análise a etnografia nos interstícios, que se assenta na indissociável relação entre teoria e prática, sujeito pesquisador - sujeito pesquisado. Efetiva-se através da observação de um Projeto de Formação de Lideranças Quilombolas para o exercício do Controle Social desenvolvido entre os meses de abril a dezembro de 2015. Verificou-se que, ao acessar os saberes do campo acadêmico é (im)provável que as lideranças quilombolas inseridas nesses contextos formativos possam exercer o controle social de suas políticas públicas e transcender de sua condição de alvos do direito, para sujeitos sociais que se organizam na busca e efetivação de tais direitos de forma mais autônoma.

Palavras-chave: Quilombola. Controle Social. Etnografia nos interstícios. Maranhão

\begin{abstract}
This research analyzes the relationship of production of knowledge built in integrative formative processes of the academic world to the universe of the quilombola struggles in theS tate of Maranhão. It takes as a privileged methodology for suchan analysis the ethnography in the interstices, which is based on the inseparable relationship between theory and practice, researcher - researched subject. It is effective through the observation of a Quilombola Leadership Training Project for the exercise of Social Control developed between the months of April to December 2015. It was found that, when accessing the knowledge of the academic field, it is (im) likely that quilombola leaders inserted in these formative
\end{abstract}

\footnotetext{
1 Professora adjunta da Universidade Estadual do Maranhão, membro do corpo permanente do programa de Pós-Graduação em Desenvolvimento Socioespacial e Regional. Coordena a Licenciatura Intercultural para a Educação Básica Indígena/UEMA. Coordenadora do Grupo de Estudos, Pesquisa e extensão em Lutas Sociais, Igualdade e DiversidadesLIDA/UEMA. Cientista Social pela UFMA (1995) com Mestrado em Sociologia pela Universidade Federal do Ceará (2001) e Doutorado em Geografia pela Universidade Estadual Paulista - Campus Presidente Prudente (2012). E-mail: marivaniafurtado@yahoo.com.br.
} 
contexts can exercise social control of their public policies and transcend their condition as targets of the law, for social subjects that organize themselves in the search and enforcement of such rights in a more autonomous way.

Keywords: Quilombola. Social Control. Ethnography. Maranhão

\section{INTRODUÇÃO}

Conhecer a diversidade da problemática das questões amazônidas, tendo como eixo a política fundiária para a regularização de território quilombolas, é de suma importância, não apenas para as Ciências Sociais, que têm privilegiado tal tema nos mais diversos fóruns, como também para as instituições representativas do poder público, sendo aqui privilegiada a Universidade, enquanto produtora de saber especializado e com "compromisso social".

Hoje, na era da globalização, a gestão do território assume novos contornos e compartilhamentos e se vincula aos interesses do mercado. Nessa nova configuração de interesses, por vezes díspares da economia global, as barreiras espaciais cedem e se criam lugares globais que representam fragmentações do espaço territorializado por Estados-nações. Tal processo tem um impacto nas territorialidades específicas que também disputam o "território nacional", aqui tratando especificamente das comunidades étnicas que se formaram no processo histórico de luta contra a escravidão, as chamadas "comunidades remanescentes de quilombos".

Embora o processo de uniformização territorial se engendre sobre espaços múltiplos, enfrenta a realidade histórica de cada grupo social, as desigualdades em seus desenvolvimentos, suas distintas formas simbólicas e níveis sociais. Essas realidades tornam-se irredutíveis às políticas homogeneizadoras tanto culturais, quanto territoriais, o que impulsiona um repensar das práticas e a implementação de novas formas de gestão de territórios. Isso deve se refletir em políticas públicas específicas e que, de certa forma, estabeleçam estratégias que garantam a participação dos representantes do público-alvo dessas políticas.

A conformação histórica de demarcação espacial influencia, sobremaneira, nas ocupações coletivas e como estas entendem o "viver", ou seja, como dão significados à sua existência social, cultural e política. Sobretudo quando entendemos que essa forma de viver, afirma-se como resistência àquilo que Maldonado-Torres (2007) define como "colonialidade do ser". Para esse autor, o surgimento desse conceito evidencia os efeitos da colonialidade, não só na mente, mas também nas experiências vividas dos sujeitos subalternizados.

Dessa forma, o Maranhão, enquanto um espaço político, formalmente constituído, apresenta uma intensa diversidade quanto ao uso e ocupação territorial. Em seus aspectos populacionais, tem sido território de disputa de nações indígenas, regionais e quilombolas. Tais disputas podem ser analisadas à luz da ecologia política ao entender que essas relações conflituosas que se estabelecem entre esses segmentos etnicoraciais específicos e os interesses hegemônicos da lógica do sistema-mundo colonial/moderno são fruto da tentativa de assimilação de lógicas simbólicas e territoriais próprias à dinâmica do mercado. Para Leff:

A ecologia política se estabelece no campo dos conflitos pela reapropriação da natureza e da cultura, ali onde a natureza e a cultura resistem à homologação de valores e processos (simbólicos, ecológicos, políticos) incorporáveis e a serem absorvidos em termos de valor de mercado. (LEFF, 2006:304) 
Para entendermos a problemática da presença quilombola no Maranhão e suas lutas por direitos territoriais, que vão além da mera formalização da regularização fundiária, pois reinvindicam condições concretas, sociais e ambientais de se manterem enquanto territórios de bem viver, necessário se faz construí-la enquanto objeto de estudo. Para tanto, devemos superar as pré-noções e transformar o problema social em problema sociológico, pois como afirma Bourdieu:

Não é possível evitar a tarefa de construir o objeto sem abandonar a busca por esses objetos pré-construídos, fatos sociais separados, percebidos e nomeados pela sociologia espontânea, ou "problemas sociais" cuja pretensão a existirem como problemas sociológicos é tanto maior na medida em que têm mais realidade social para a comunidade dos sociólogos. (BOURDIEU, 2004:47)

No Maranhão, atualmente, como será explicitado em seguida, existe uma forte presença de comunidades quilombolas. Oficialmente somos o maior Estado do Brasil em número de comunidades reconhecidas pela Fundação Cultural Palmares. Embora esse reconhecimento seja fruto da articulação política dos movimentos negros no Estado, não se observa, ainda, uma autonomia das próprias lideranças quilombolas na condução formal dos trâmites processuais quanto à titulação dos territórios e a efetivação de políticas públicas.

Acreditamos que essa situação advem das próprias condições histórico-simbólicas da formação das territoraildades quilombolas, uma vez que o modo de viver nos quilombos não implica, necessariamente, na necessidade de conhecimentos formais acadêmicos. Ademais, em cada formação identitária quilombola um léxico próprio se configura, o que tem afastado os campos semânticos entre o universo dos quilombos e o campo jurídico. À guisa de exemplo, ao se referirem às prestações e compromissos assunidos enre si, os quilombolas da Baixada Maranhense, campo empírico desta pesquisa, chamam isso de "teu direito". Dito de outra forma a obrigação, ou dever de cada um é chamado de direitos e não dever. Exemplificando o uso desse sentido, temos o seguinte contexto: "foi ele que deixou o porco entrar na roça, então é o direito dele pagar o prejuízo".

Diante dessa situação, temos o seguinte problema sociológico: como discutir direitos já pactuados constitucionalmente com um determinado segmento social se os sujeitos de direitos aos quais se referem não dominam efetivamente a liguagem escrita? Além do mais, como socializar com esses sujeitos o que lhes é garantido formalmente, se o próprio significado de dieitos para essas comunidades se refere ao seu contrário, isto é; o direito como dever? Tais questões nos levaram a formular o projeto de pesquisa/extensão, objeto aqui desta análise e que será mais adiante explorado.

A siginificativa presença de comunidades quilombolas no Maranhão atual resulta do processo histórico de ascenção econômica desse território, sobretudo no século XVIII. A partir da fundação da Companhia do Comércio do Grão Pará e Maranhão, emprendimento comercial implementado pela gestão pombalina na segunda metade do século XVIII, houve um crescimento significativo de escravos africanos na região. Até 1755 , calcula-se que entraram 3 mil escravos no Maranhão.

No período de existência da Companhia, entre 1755 e 1777, este número saltou para 12 mil. Segundo Assunção (1996) os quilombos enquanto formações socioespaciais e cultuais só se tornaram um "um fenômeno endêmico da sociedade escravista com a chegada da grande quantidade de 
escravos nos últimos anos daquele século". (ASSUNÇÃO,1996:436)

Como resultado desse processo, conta-se que a população maranhense, naquele peíodo, era composta de 55\% de africanos escravizados. Tal estatística correspondia a mais alta porcentagem de população escravizada no Império.

Mesmo não sendo possível precisar a quantidade de quilombos existentes desde esse período até a abolição da escravatura, tem-se afirmado que no Maranhão haviam poucas fazendas escravistas sem quilombos à sua volta.

A história de formação de tais ocupações territoriais varia. Alguns quilombos históricos se originaram da fuga dos cativos, enquanto outros por meio de compra ou herança de terras, conquistadas após longo período de trabalho escravo, outras pelo abandono dos senhores após crises econômicas, dentre outras situações. Seja qual tenha sido o caminho para sua formação, o quilombo possibilitou aos africanos e afrodescendentes escravizados passarem da condição de escravos para a de camponeses livres (Cf. ALMEIDA, 2008).

Como resultado de todo esse processo histórico, as comunidades quilombolas representam hoje, como dito anteriormente, um significativo percentual da população maranhense pois, conforme cadastro junto à Fundação Cultural Palmares, são computadas 816 comunidades certificadas $^{2}$ como remanescentes de quilombos, cujos territórios estão localizados, principalmente, nas regiões norte e central do Estado.

Essas comunidades são portadoras de direitos constitucionais, quanto ao título de propriedade definitiva de seus territórios e, embora consubstanciadas em modos de vida determinantes de uma definição prévia como "comunidade remanescentes de quilombos", a existência concreta de tais comunidades não revela, de pronto, que sua condição em si garantiria a inserção no plano dos direitos formais já pactuados.

Necessário se faz que tais comunidades transcendam da condição de sujeitos concretos, alvos de direitos, para sujeitos sociais que se organizam na busca e efetivação de tais direitos. Retomando uma definição marxista, essas comunidades sairiam de uma condição "em si”, para a conquista e redefinição de uma história "para si".

Tal movimento, nessa perspectiva, poderia ser entendido como aquilombamento contemporâneo. De acordo com Furtado (2018), o aquilombamento contemporâneo se gesta na atualidade mediado pelas relações socioeconômicas, culturais e políticas conflituosas entre agentes antagônicos que determina múltiplas formas de resistência das comunidades quilombolas e outros sujeitos sociais à essas estruturas dominantes.

A partir dessa situação problema, este estudo analisa como os sujeitos do direito territorial quilombola têem-se articulado para a garantia e efetivação desse direito específico, considerando sua condição histórica de exclusão dos processos formais de acesso a conhecimentos sobre tais direitos. Dito de outra forma, como esses sujeitos têem-se constituído em lutas territoriais e formação de lideranças se os mesmos não sabem que são possuidores de tais direitos e qual o papel da Academia nesse processo?

Para que as Políticas Públicas propiciem ganhos para a sociedade como um todo (seja inclusiva e universal), é fundamental que os diversos atores interessados, aqui especificamente os quilombolas, participem da sua construção, assim como do processo de monitoramento e avaliação de tais políticas específicas, ou seja; exerçam o efetivo controle social.

Esta pesquisa reflete, portanto, sobre quais mecanismos de controle social podem/deve ser

${ }^{2}$ Conforme site da Fundação Cultural Palmares. Disponível em: http://www.palmares.gov.br/?page_id=37551. Acesso em 08 de maio de 2020 . 
socializados através dos movimentos sociais e academia junto a lideranças quilombolas a fim que lhes permitir um empoderamento para o pleno exercício do seu papel de agentes proponentes e fiscalizadores das ações públicas, sobretudo, mas não somente, no que diz respeito à política de regularização fundiária dos seus territórios étnicos.

\subsection{Por uma reflexão teórico metodológica}

A discussão da questão do direito territorial quilombola toma por base categorias que apresentam uma abordagem elucidativa e atual sobre essa temática. Com esse intento, apresentamse os conceitos de território e controle social como concepções articuladas teoricamente, para embasar o estudo e interpretação das demandas apresentadas pelas comunidades quilombolas junto ao poder público para a regularização fundiária de seus territórios e demais políticas públicas a elas destinadas.

De início cabe ressaltar que tomaremos a noção de território proposta por Silva (2004) quando esta afirma que:

[...] o território não diz respeito apenas ao espaço geográfico, físico, mas também ao espaço simbólico, que o envolve com significados da cultura e da vida social ali existente. Há uma simbiose entre a natureza e o humano. A natureza é um prolongamento do humano, portanto é o complemento indispensável à sua vida. (SILVA,2004:25)

A conceituação proposta por essa autora nos permitirá entender a luta quilombola no Maranhão por seus territórios. Almeida (2002) coloca como critério de demarcação conceitual dos territórios quilombolas, enquanto territórios étnicos, suas múltiplas formas de uso e apropriação da natureza, cujas singularidades configuram territorialidades específicas com etnicidades contitutivas.

A outra categoria que será norteadora deste estudo é a de controle social. Aqui essa categoria será apropriada na sua forma atualizada que se contrapõe à noção clássica de controle social como estratégias desenvolvidas pela sociedade visando a formação do comportamento normal dos indivíduos evitando os desvios. Tal perspectiva clássica durkheiminana tem sido o aporte para o tratamento do controle que os órgãos da segurança pública exercem sobre os indivíduos de uma dada população.

A noção de controle social, aqui retomada, terá foco na inversão dessa relação Estado sobre a sociedade e será centrada sobre a relação da sociedade civil organizada no controle das ações do Estado no exercício das políticas públicas. Conforme Calvi (2008):

Nas últimas décadas, o termo controle social passou a fazer parte do vocabulário dos brasileiros. Geralmente o sentido dado a este termo está ligado à possibilidade da sociedade civil1 organizada participar dos momentos de proposição, elaboração, fiscalização e implementação das políticas sociais. Este significado, dado ao termo controle social, emerge a partir da década de 1980 num contexto de luta dos movimentos sociais pela redemocratização da sociedade e do Estado brasileiro. (CALVI,2008:10)

O controle social, portanto, é uma estratégia democrática de participação no acompanhamento das ações do poder público, identificando gargalos e focando aspectos que contribuam para a melhoria da execução das ações, buscando assim garantir o atendimento de demandas 
específicas.

Este estudo propõe uma abordagem metodológica específica, a saber; a etnografia nos interstícios. Tal metodologia é fruto da própria experiência da pesquisa e tem em seu alicerce uma crítica aos dualismos positivistas da separação entre sujeito/objeto e pesquisa/extensão como partes opostas dos processos de investigação e intervenção da realidade social.

A etnografia no instertícios nos permite compreender e transformar a realidade social, como partes do mesmo processo reflexivo sendo, portanto, indissociáveis. Para tanto, nos valemos das estratégias da observação situada nos encontros que aconteceram nas comunidades quilombolas, bem como nas etapas previstas no Projeto de Formação Quilombola para o Controle Social, desenvolvido por esta pesquisa em 2015, como lócus de análise e intervenção da realidade.

\section{O CONTEXTO DO MOVIMENTO SOCIAL QUILOMBOLA NO MARA- NHÃO E A PERSPECTIVA DO CONTROLE SOCIAL}

Utilizaremos em todo texto o verbo na primeira pessoa do plural a fim de contemplar os diversos sujeitos que participaram na construção deste percurso analítico. Registramos isso, pois de forma direta e indireta os sujeitos pesquisados não somente foram autores dos "dados" aqui trabalhados, como também participaram das estratégias reflexivas que permitiram a análise aqui proposta.

Compreendemos que o surgimento de movimentos sociais que se direcionam para a causa "quilombola" no Maranhão se configurou diante de uma realidade de violência e invisibilidade sofridas por esse segmento étnico específico. Agências específicas foram criadas para "dialogar" com o poder público como a Associação das comunidades negras, rurais e quilombolas do Maranhão - ACONERUQ3 , ou articulações sociopolíticas voltadas para o "confronto" direto com o poder como o Movimento Quilombola do Maranhão - MOQUIBOM 4 e se estabeleceram, sobretudo este último, como contra hegemonia diante de um Estado que se construiu sobre as bases da desigualdade e da exclusão.

A conquista de garantias jurídicas, como o Artigo 68 da ADCT- CF se deu pela força da sociedade civil organizada que se fez ouvir através de seus movimentos sociais organizados. Tais movimentos tiveram expressão, sobretudo no período da Constituinte de 1987-1988, tanto em plano local quanto nacional.

Como fruto dessa pressão, tivemos dispositivos constitucionais que asseguraram, ao menos no plano formal, direitos aos quilombolas que lhes permitiram sair do contexto de total exclusão ao qual estavam inseridos. Desta forma podemos concluir, como afirma Santos (1999), que a atual preocupação por parte do Estado em fazer uma gestão controlada dos dois grandes problemas provenientes do Estado Moderno, a saber: a desigualdade e a exclusão não foi, uma iniciativa autônoma dessa instituição dita "democrática de direitos":

A gestão controlada das desigualdades e da exclusão não foi, em nenhum momento, uma iniciativa ou uma concessão autônoma do Estado capitalista. Foi antes o produto de lutas sociais que impuseram ao Estado políticas redistributivas e formas menos extremas de exclusão. E, do mesmo modo, a crise atual desta gestão controlada, protagonizada pelo Estado nacional, que

3 A ACONERUQ foi criada em 1997 pelo Centro de Cultura Negra do Maranhão/CCN-MA.

${ }^{4}$ O MOQUIBOM ganhou visibilidade enquanto articulação de comunidades quilombolas no Maranhão em 2011.

PRACS: Revista Eletrônica de Humanidades do Curso de Ciências Sociais da UNIFAP 
acima analisei, bem como as novas formas e metamorfoses do sistema de desigualdade e do sistema de exclusão são produtos de lutas sociais, tal como o serão as possíveis evoluções futuras da situação em que nos encontramos. (SANTOS, 1999: 43)

Como representante hegemônica da luta quilombola no Estado até o ano de 2011 a ACONERUQ pautava a necessidade de reparação histórica, diante da grave situação de insegurança jurídica territorial e dos recorrentes conflitos no campo maranhense envolvendo essas comunidades. A partir do primeiro semestre de 2011 entra em cena outro ator coletivo que se colocava também como representativo das demandas quilombolas no Maranhão, a saber o MOQUIBOM, cuja pauta centrava-se na titulação dos territórios, a fim de fazer valer "na lei ou na marra" o artigo 68 da ADCT ${ }^{5}-1988$.

Para entendermos essa dinâmica, que ao mesmo tempo se configura como disputa dos espaços legítimos de representatividade do mesmo segmento social e político, nos apoiamos em Melucci (2001) quando afirma que o agir coletivo não pode ser compreendido como ato unitário. $\mathrm{O}$ autor nos direciona para a compreensão da pluralidade de significados, orientações e relações dentro de um mesmo fenômeno coletivo, aqui, especificamente, os movimentos quilombolas no Maranhão.

O surgimento do MOQUIBOM, enquanto movimento social também representativo das comunidades quilombolas maranhenses, nos permite visualizar a complexidade das ações coletivas estabelecidas e como estas se configuram através de processos sociais heterogêneos. Isso acentua que a agenda dos movimentos sociais vai sendo redefinida historicamente e politicamente de acordo com os compromissos assumidos diante do mesmo quadro de insatisfação frente à omissão do Estado em efetivar o direito constitucional já pactuado.

Outro fator determinante para o "ressurgimento" da pauta pela titulação dos territórios quilombolas deveu-se ao recrudescimento dos conflitos no campo vivenciados em 2010 . Naquele ano uma liderança quilombola da região da Baixada Maranhense, integrante da luta pela titulação do território de Charco/Juçaral do Município de São Vicente de Férrer, foi barbaramente executado com seis tiros a queimar roupa em uma emboscada patrocinada pelo pretenso proprietário da terra em disputa.

$\mathrm{O}$ assassinato de Flaviano Pinto Neto aglutinou mais de cem comunidades quilombolas para atuarem em fechamentos de estradas, romarias, ocupações de prédios públicos, dentre outros. Tais ações acentuavam-se como forma de resistência à situação de violência e exclusão de direitos manifestos nesse e em outros casos semelhantes.

Ao acompanharmos diretamente essas ações de mobilização e pressão junto ao poder público observávamos que, geralmente, quando da interlocução mais direta com os representantes dos órgãos responsáveis pelas políticas para o setor quilombola, as lideranças do movimento delegavam aos “assessores” (padres, advogados, militantes partidários ou sindicais, pesquisadores das Universidades, dentre outros) a mediação do diálogo.

Isso era fato quando o poder público requeria do movimento a "pauta de reivindicações", uma exposição oral dos temas da reunião ou quando ficava a cargo do movimento a confecção de atas de acordos firmados. Essa dependência dos saberes especializados dos "apoiadores" nos causava incômodo e nos levava a refletir sobre a importância de se estabelecer um processo formativo sistemático a fim de que os quilombolas se apropriassem de certos saberes relacionados ao mundo acadêmico e aos trâmtites burocrático institucionais. Com esse intento,

5 Ato das disposições constitucionais transitórias de 1988 
acreditávamos que poderia ser amainada a dependência dos quilombolas dos "apoiadores externos" na mediação entre o mundo formal e as dores concretas de sua realidade excludente.

Diante desse quadro, vislumbramos a realização de oficinas com lideranças tanto do MOQUIBOM, quanto da ACONERUQ para exercício do controle social autônomo, objetivando o empoderamento dessas lideranças frente ao poder público e mesmo de seus apoiadores. Ao propormos tal projeto formativo entendíamos estar entrando num jogo político de disputa pelo ato de ver e dividir o mundo social, como afirma Bourdieu (2011):

(...) eu disse que o campo político podia ser descrito como um jogo no qual o que está em disputa é a imposição legítima dos princípios de visão e divisão do mundo social.(...) As lutas políticas envolvem disputas intelectuais, princípios de visão e de divisão (...) O que está em disputa no jogo político é o monopólio da capacidade de fazer ver e de fazer crer de uma maneira ou de outra. (BOURDIEU,2011:206)

Nossa maneira de crer pontuava que, mesmo nosso saber partindo do mundo acadêmico não deveria sobrepor-se aos conhecimentos tradicionais dos quilombolas, ao contrário, deveria complementá-lo diante do desfio de "dialogar" com o poder público. Tal perspectiva teórico política embasou o projeto que denominamos de Formação Quilombola para o exercício do Controle Social.

\subsection{Formação quilombola para o controle social: transformando sofri- mentos em armas de luta}

Ao propormos o "Projeto de Formação quilombola para o exercício do Controle Social6" objetivávamos responder a uma indagação teórica e ao mesmo tempo pragmática: como os quilombolas acessariam direitos dos quais não tinham conhecimento? Questionávamos-nos, também, sobre como "partilhar" esses saberes sem cairmos numa esfera de negação das formas próprias de racionalidade tradicional ou quilombola, como por exemplo o entendimento do direito como dever próprio do léxico das lideranças?

Optamos, portanto, pela proposta do diálogo processual. Articulamos com uma das principais lideranças do MOQUIBOM com a qual a coordenação desta pesquisa tem laços mais próximos para ser o interlocutor privilegiado entre o Projeto e as lideranças do movimento. Aquela liderança do município de Mirinzal-MA demonstrou desde o início das tratativas, para a análise da viabilidade do Projeto, um forte interesse em garantir a realização das oficinas de controle social, por entender que essa seria uma estratégia consequente para o empoderamento das lideranças do MOQUIBOM.

Essa liderança se constitui naquilo que Muniz (2014) identifica como mediador orgânico. Nas considerações desse autor, mediadores orgânicos são aqueles que emergem como sujeitos políticos, situados entre o saber tradicional da própria comunidade, acumulado pelo processo de socialização de seu próprio grupo e outros conhecimentos, linguagens "que estão além da

\footnotetext{
${ }^{6} \mathrm{O}$ referido projeto foi apresentado à Fundação de Amparo à Pesquisa do Maranhão, no ano de 2014, através do Edital Universal. Objetiva, através da metodologia da pesquisa-ação, analisar o processo de formação de 30 lideranças quilombolas inseridas nos movimentos quilombolas do Maranhão. Tinha como equipe executora o Grupo de estudos, pesquisa e extensão em Lutas sociais, Igualdade e Diversidades-LIDA da Universidade Estadual do Maranhão. O projeto foi executado no período de 2014 a 2016 e resultou em oficinas de formação de lideranças quilombolas, monografia de conclusão de curso em Ciências Sociais, artigos científicos e comunicações orais em eventos acadêmicos.
} 
microesfera, além de sua comunidade, administrando a interlocução entre a existência dos grupos em si e como estes devem proceder para garantir direito. "(Muniz, 2014:43).

De forma autônoma e parceira essa liderança do MOQUIBOM, assim como as da ACONERUQ, que desde a primeira tratativa para a efetivação das oficinas demonstraram total interesse no Projeto, tornou-se um dos principais interlocutores para a efetivação das oficinas de controle social.

Atualmente entende-se por controle social, em contraposição à perspectiva clássica do exercício da coerção do estado sobre a sociedade, como dito anteriormente, sua inversão, pois segundo Kolody (2004):

Trata-se da interferência da sociedade civil na gestão, tanto no que se refere ao planejamento quanto à execução e avaliação dos serviços públicos visando ao interesse público, uma forma específica de participação da sociedade em relação direta com o Estado. Pode-se inferir que as características da participação funcionam como aspecto fundante da categoria controle social, já que o controle social é entendido neste estudo como totalidade concreta, enquanto construção que supera a condição de fiscalização. (KOLODY,2004:143)

A realização das oficinas junto aos quilombolas partiu da perspectiva do controle social enquanto uma totalidade concreta, que pressupõe não só a fiscalização, por vezes exercida pelos próprios aparatos do Estado, mas também a participação efetiva dos sujeitos de direitos. Para tanto tais atores carecem de elementos informativos específicos.

Entre os meses de abril e maio de 2015 iniciamos os encontros com lideranças quilombolas em três comunidades nos municípios maranhenses de Mirinzal, Brejo e Bequimão. Além desses encontros, realizamos reuniões de trabalho com a ACONERUQ em sua sede administrativa em São Luís. O objetivo desses encontros e reuniões era apreender do "público-alvo" do Projeto suas expectativas quanto à metodologia e conteúdos a serem ministrados nas oficinas de controle social.

As discussões nas comunidades nos permitiram não somente observar, mas nos situar no mundo e nos sofrimentos dos sujeitos partícipes do Projeto. Esse trabalho de campo possibilitou-nos articular a pesquisa acadêmica à intervenção qualificada, visando o empoderamento das lideranças quilombolas para o exercício do controle social.

A realização das oficinas, propriamente ditas, aconteceu entre os meses de maio a dezembro de 2015 e culmina com a certificação dos participantes em 100h de trabalhos realizados. As ações formativas dividiram-se em 3 etapas de atividades presenciais, com 20h cada, e 2 etapas de atividades de pesquisa e articulação nas comunidades, com $20 \mathrm{~h}$ cada.

\subsubsection{Para "abrir o caminho" do diálogo entre a Academia e o movi- mento social quilombola}

Para estreitar o diálogo entre os campos semânticos da Universidade com o movimento social quilombola, realizamos entre os dias 26 e 27 de maio de 2015, uma reunião classificada como "preparatória" para as oficinas. Esse encontro contou com mais de 50 quilombolas que têm seus territórios situados em mais de 20 municípios do Maranhão.

A dinâmica utilizada nesse encontro preparatório foi a da intervenção dialogada. Fizemos uma exposição do conceito de "controle social" e em seguida solicitamos que os participantes se reunissem em grupos para escreverem o que esperavam aprender naquele Curso. O objetivo 
dessa atividade era aproximar os campos semânticos: quilombola e acadêmico. Adotamos essa diretriz a fim de superar a perspectiva do totalitarismo epistemológico (Santos, 1997) que reduz todas as outras formas de ser, estar e interpretar o mundo como não científicas, pré-modernas ou não-racionais.

Corroborando com Santos, Mignolo (2003) afirma que:

O que está realmente em causa é a "ciência moderna" ser uma prática e uma ideologia que exclui práticas de conhecimento e de compreensão que se guiavam por diferentes lógicas e eram impulsionadas por objetivos distintos, tanto do passado como suas contemporâneas. A "Ciência" tornou-se o padrão de aferição para "excluir" qualquer forma de conhecimento e compreensão que não fosse considerada "científica". (MIGNOLO,2003:705)

$\mathrm{Na}$ fala de uma das lideranças participantes dessa etapa preparatória apreendemos a importância desse cruzamento de saberes. Relatou sobre o grande pesar que é pensar na realidade de sua comunidade, nas dificuldades enfrentadas em prol da conquista de seus direitos. Ao término de sua fala, expôs que sempre teve muita vontade de participar de um Curso como o que estava sendo proposto.

Esse encontro preparatório nos permitiu “abrir o caminho" para planejarmos os temas/ conteúdos que seriam trabalhados nas etapas de efetivação dos Seminários de Formação em Controle Social.

\subsubsection{Das experiências cruzadas dos saberes compartilhados nas ofici- nas de Controle Social}

Como desdobramento das atividades da etapa de maio, realizamos entre os dias 9 a 11 de julho de 2015 a etapa de discussão dos temas propostos no encontro preparatório da Formação em Controle Social. Nesses três dias de trabalhos foram realizadas atividades sobre os seguintes conteúdos: identidade étnica, associativismo, políticas públicas para quilombolas e o direito territorial previsto na Constituição Federal de 1988.

O tema da Identidade Étnica foi abordado através de uma exposição sobre os quilombos no Maranhão, a história e os processos de identificação étnica. Discutiu-se sobre a colonização do Brasil, a utilização da mão de obra escravizada e extermínio dos indígenas, destacando-se a inserção da mão de obra africana no Brasil e os processos de resistências dos africanos e seus descendentes ao sistema escravagista ao se organizarem em quilombos.

Intercalando-se às exposições utilizamos cânticos que expressam, na atualidade, a luta e resistência dos quilombolas: "O negro mora em palafita. Não é culpa dele, não senhor. É culpa da abolição que veio e não o libertou. Dança aí, negro nagô, dança aí negro nagô."

Como "exercício" prático dos conteúdos trabalhados nessa oficina, solicitamos dos participantes que, organizados em grupos, elaborassem textos em linguagens distintas sobre a temática discutida. Como resultado dessa atividade proposta, os quilombolas elaboraram um vídeo-denúncia, uma canção e um poema.

O tema do associativismo foi tratado por meio da dinâmica da fala dialogada. Os facilitadores solicitaram que os participantes confeccionassem cartazes com seus entendimentos ini-

${ }^{7}$ Canto intitulado Negro Nagô, entoado nas místicas do movimento negro, composto pela Pastoral da Juventude da Igreja Católica. 
ciais sobre o tema. A partir dessa estratégia, muitas lideranças expuseram seus conhecimentos sobre o que era associação e em suas falas acabavam expondo as histórias de suas lutas e dificuldades enfrentadas em suas comunidades. Outro ponto discutido, nessa etapa de formação, versou sobre o direito territorial quilombola. A proposta consistiu em levar o conhecimento jurídico para as lideranças e contou com a exposição deum folder contendo o "passoa-passo" do processo para titulação de territórios quilombolas. Trabalhamos também com a Constituição Federal sobre o direito territorial previsto no artigo 68 da ADCT. Distribuímos entre os participantes exemplares da carta Magna.

Essa etapa de formação foi encerrada com o planejamento das ações que aconteceriam na etapa intermediária, a saber: Encontros nas comunidades quilombolas, bem como uma avaliação da realização desse momento formativo. Ficou decidido que no mês de agosto, a equipe proponente do Projeto realizaria visitas de acompanhamento aos participantes, em suas comunidades, para discutir os assuntos tratados nessa primeira etapa. Seria também objetivo das atividades nas comunidades o planejamento dos conteúdos que seriam trabalhados na etapa presencial seguinte, a ser realizada em dezembro de 2015.

\subsubsection{O trânsito das oficinas: a experiência na comunidade Rio do Cur- ral}

A problemática da ausência de saberes jurídicos, institucionais ou mesmo de textos oficiais, das lideranças quilombolas em contexto de aquilombamento verificada no desenvolvimento desta pesquisa, definiu as estratégias das ações que visavam novas inserções no campo empírico, a saber, atividades a serem realizadas diretamente nas comunidades quilombolas envolvidas no Projeto.

Durante a etapa anterior do Projeto de Formação ficou definido, juntamente com as lideranças participantes do Projeto, visitas a quatro comunidades quilombolas, a saber: Moreira em Itapecuru-Mirim, Rio Grande em Bequimão, Vila das Almas em Brejo e Rio do Curral em Mirinzal. O intuito era estabelecer maior proximidade com a realidade e possíveis enfrentamentos vivenciados por estas lideranças em suas próprias comunidades para, desta forma, socializar saberes para contribuir com suas demandas locais.

Utilizamos como estratégia para a elaboração da etnografia nos interstícios, a experiência da condução da oficina em Controle Social na comunidade de Rio do Curral. Essa comunidade fica situada no município de Mirinzal e abrigou nos dias 15 e 16 de agosto uma oficina para tratarmos da redação de textos oficiais.

Argumentamos inicialmente que "as palavras de boca têm um peso muito pequeno para as autoridades, por isso elas tem que ir pro papel”. Antes de tratar da redação de textos oficiais, percebemos a necessidade de discutir os conceitos básicos referentes ao contexto quilombola tais como: quilombo, território e direito territorial.

$\mathrm{Na}$ fala de um dos presentes verificamos a importância de "traduzirmos" os conceitos acadêmicos ao universo semântico das comunidades tradicionais. Assim comentou um quilombola presente na oficina: "Ninguém nem sabia que palavra era essa quilombola e aí pra gente saber no que ela tá ditando, a gente tem que tá junto com as outras pessoas que sabem pra poder explicar pra gente".

Outra fala acentuava que para se ter acesso a saberes que se direcionam para questão quilombola é necessário sair da comunidade e ter contato com outros ambientes para obter esclarecimentos sobre tais assuntos, para ter firmeza quanto a sua condição de quilombola, de 
identificar-se como sujeito de direito.

Paul Gilroy (2001) em o Atlântico Negro, ao tratar da expansão da consciência como característica da modernidade, expõe que ser negro e europeu requer dupla consciência. Para ele discursos racistas, nacionalistas e etnicamente absolutistas com suas determinações e relações políticas de identidade exclusiva e delimitada concebem a continuidade de identidade e sua dinamicidade como insubordinação política, como um ato provocador.

Ao reforçar o discurso da dominação, exatamente por não saber que se inserem nesse jogo desigual, muitos quilombolas não "sabem", ou não "assumem”, essa identidade para não ser vítimas das punições pelos atos "provocadores".

Iniciamos, após as discussões conceituais, o momento "prático" da oficina com a produção de textos oficiais. Como já mencionado anteriormente, em muitas situações a elaboração de documentos formais, quando dos atos mobilizatórios dos quilombolas, é feita por aqueles que se caracterizam como os mediadores externos, ou seja, não quilombolas apoiadores da causa (padres, advogados, militantes partidários, acadêmicos, dentre outros). Além do texto escrito fazem também a interlocução entre as comunidades e os agentes de Estado.

Andrade (2009) afirma que desde que o Estado reconheceu sua dívida com as comunidades quilombolas ao inserir o Artigo 68 na Constituição de 1988, pouca atenção tem se direcionado para o fato de que esses grupos, para existirem publicamente, passaram a depender de uma rede de mediadores externos que ao longo do tempo foram responsáveis pela interlocução política entre as comunidades e as instituições do Estado.

[...] para existirem publicamente, para realizarem a interlocução política com instituições supracomunitárias, esses grupos passaram a depender de toda uma rede de mediadores, desde aqueles que foram erigidos como seus próprios representantes, aos antropólogos (que foram aclamados a dizer quem eram esses sujeitos de direitos), aos advogados (atuando em entidades não governamentais ou dentro do próprio Estado), aos funcionários de órgãos oficiais, aos gestores públicos e de empresas. Enfim, agentes especializados no que se poderia denominar questão quilombola, passaram a deter autoridade para dizer quem são, onde e como vivem e quais os direitos desse grupo. (ANDRADE, 2009: 44)

Com base nessa reflexão, iniciamos a confecção de textos oficiais: ata de reuniões e pauta de reivindicações, por serem estes os instrumentos mais utilizados pelas lideranças em "diálogo formal com o poder público”. A justificativa para a realização dessa atividade advinha do desconhecimento que as lideranças apresentavam desses saberes e da necessidade de deles se apropriarem para terem falas (no microfone e no papel) mais autônomas e menos dependentes dos mediadores em contexto de lutas quilombolas.

O papel da academia, nesse contexto de construção de saber, verifica-se como contraditório, pois ao mesmo tempo em que permite às lideranças a possibilidade de autonomia em realizar um documento formal, pode gerar uma hierarquização interna: entre os que já sabem fazer e o que não possuem tal saber, sobrepondo-se ao saber tradicional que é "de todos". Por outro lado, ao apropriar-se de tais conhecimentos, os quilombolas podem atenuar a dependência dos mediadores externos.

As atividades da oficina resultaram na elaboração de textos formais nos quais se registraram suas dificuldades de forma "resumida" (ata de reunião) e sua história de sofrimentos sistematizada para reivindicar direitos (pauta de reivindicações). 


\subsubsection{A "Formatura" da Turma Flaviano Pinto Neto}

Esta última etapa da experiência com a formação em controle social para lideranças quilombolas, realizou-se entre os dias 29 de novembro a 01 de dezembro de 2015.

Nesse encontro realizamos oficinas que trataram de temas que surgiram nas comunidades e mostravam-se urgentes aos contextos de lutas quilombolas. Tais temas foram: mídia e poder, textos oficiais (ata, pauta de reivindicações e requerimento) e questões jurídicas sobre a terra.

A oficina de Mídia e Poder foi coordenada pelo jornalista e editor do Jornal Popular Vias de Fato que tratou, de forma dialogada, sobre as questões do poder e da participação das grandes mídias no silenciamento ou criminalização dos movimentos sociais. Discutiram-se propostas alternativas para visibilizar as lutas e sofrimentos dos quilombolas participantes da oficina. Essa discussão culminou com a elaboração de cartas-denúncias pelos participantes que apresentaram a situação de suas comunidades e os conflitos nelas existentes. Esse material foi publicado no referido Jornal local.

A discussão sobre o papel da mídia junto aos participantes teve como objetivo o empoderamento das lideranças sobre os canais alternativos para expor suas lutas, pois como afirma Scherer-Warren (2008) a rede de movimentos sociais:

Será forte se incluir uma história que persuade e integra seus membros; se abranger estratégias e métodos colaborativos baseados em uma doutrina bem definida; se utilizar sistemas avançados de comunicação e apoiar-se em vínculos sociais e pessoais fortes. (SCHERER-WARREN, 2008: $6)$.

Comenta ainda que novas formas de tecnologias têm um caráter significativo para a formação de uma sociedade civil mais ampla e mundializada. Movimentos específicos têm se beneficiado, dentre outros recursos, de redes virtuais tanto para comunicação quanto para "formação de uma 'opinião pública mundial' a partir de uma sociedade crítica". (Scherer-Warren, 2008, p.7). Mesmo não sendo o principal elemento mobilizador de um movimento, Warren expõe que as novas formas de comunicação têm facilitado a propagação das narrativas e ideários em construção pelos sujeitos.

No dia seguinte retomamos as discussões sobre a questão da regularização fundiária. Decidimos tratar novamente desse tema, pois muitas lideranças presentes apresentaram demandas de regularização dos seus territórios “como quilombolas”, sendo que alguns já seriam regularizados como assentamento da reforma agrária.

Diante desse contexto apresentamos os dispositivos constitucionais que tratam tanto da sistemática da desapropriação de terras para fins de reforma agrária, como para a titulação definitiva das terras ocupadas pelos remanescentes de quilombos.

Observamos que apesar de algumas manifestações dos participantes de estarem compreendo "os assuntos" tratados, era visível também certa incompreensão dos termos, ou conteúdos trabalhados. Essa situação demonstra o quanto o "campo jurídico" se constitui de forma hermética aos não "iniciados".

Bourdieu (2004) afirma que o campo jurídico consiste num sistema fechado, onde somente "os de dentro" compreendem seu desenvolvimento.

A ciência jurídica, tal como a concebem os juristas e, sobretudo, os historiadores do direito, que identificam a história do desenvolvimento interno dos seus conceitos e dos seus métodos, apre- 
ende o direito como um sistema fechado e autônomo, cujo desenvolvimento só pode ser compreendido segundo a sua dinâmica interna (BOURDIEU, 2004: 209)

O campo Jurídico constitui-se, para esse autor, como um espaço de concorrência pelo monopólio de dizer a boa ordem, o direito. Dentro desse campo existem aqueles que teriam a capacidade de interpretar de forma autorizada os textos mormativos e consagrados como a visão legitimada e justa sobre o mundo social.

Após essa atividade iniciamos uma oficina de "redação de textos oficiais". Antes da feitura desses textos, solicitamos que os participantes se dividissem em grupos e simulassem situações de confronto com o poder público, a fim de visualizarem os distintos contextos e quais documentos seriam requeridos em cada situação conflituosa.

Cada grupo criou um roteiro e encenou situações onde deveriam ser apresentadas "atas de reuniões", "requerimentos" e "pautas de reivindicações".

Essa atividade foi desenvolvida com grande envolvimento dos participantes, pois mesmo com o "sofrimento" em ter que lidar com a escrita, a expectativa de encenar para o público a peça teatral que cada grupo criou era bastante motivadora.

Utilizamos essa dinâmica da peça teatral que resultou em textos oficiais escritos, assim como em outras oficinas anteriores nas quais solicitamos que elaborassem poemas e canções, com o objetivo de resguardar o saber da oralidade tão presente na identidade dessas comunidades tradicionais. Embora dialogando com o plano da escrita, sobretudo verificando que essa tem sido uma das principais fragilidades do movimento quilombola frente aos seus antagonistas, a valorização de outras formas de expressão da linguagem foi adotada em nosso Projeto de Formação, respeitando assim o os processos pedagógicos próprios das comunidades tradicionais.

Após esse trabalho, passamos a organizar a formatura da Turma. Os presentes sugeriram que o nome da turma deveria homenagear a liderança que tombou na luta pelo direito ao território quilombola e que se tornou símbolo, principalmente do movimento na Baixada Maranhense. Ficou, então, acordado que a turma levaria o nome de Flaviano Pinto Neto.

Decidimos também quais os representantes que tomariam assento à mesa de cerimônia da formatura representando suas articulações (MOQUIBOM e ACONERUQ), os oradores e aproveitamos para distribuir o material didático confeccionado ao longo das etapas de formação.

A cerimônia solene de formatura foi presidida pela Pró-Reitoria de Extensão da Universidade Estadual do Maranhão, a qual se vinculava este Projeto. Reiterou-se, naquela oportunidade, o compromisso da Instituição com a inclusão social dos diversos segmentos que compõe a diversidade populacional no Maranhão.

Registramos a fala de uma das formandas que pontuou sua experiência com o Projeto de Formação: "Eu fico muito feliz de ter participado desse Curso. Não pude estudar numa faculdade, porque não tive condição, meus filhos também não foram pra faculdade, porque eu não tenho como pagar..."

A realização do Projeto da Formação de Quilombolas para o Controle Social tinha por objetivo que os participantes perdessem o "medo do microfone" e "do papel", pois a partir do conhecimento adquirido eles poderiam falar por si, desvinculando-se paulatinamente da dependência dos mediadores.

A experiência com o processo de formação das lideranças quilombolas para o exercício do controle social revelou um campo importante de análise para apreender os limites e possibili- 
dades da pretendida troca de saberes entre o universo acadêmico e as racionalidades negadas do universo quilombola no Brasil e, em especial, no Maranhão.

\section{CONSIDERAÇÕES FINAIS}

Atualmente observa-se que a tentativa de exercer o controle da sociedade pelo Estado, tem passado por um revés, quando se verifica que, em processos ditos democráticos, o Estado se verga às forças provenientes da própria sociedade. Neste aspecto a Constituição Federal Brasileira de 1988 é um forte exemplo de como a ação reivindicatória e as lutas sociais exercem força sobre a dinâmica e estrutura do Estado, sobretudo quando destacamos o direito territorial quilombola assegurado no artigo 68 da ADCT.

Por outro lado, ao mesmo tempo em que se afirma o direito territorial dos quilombolas como já formalizado, a sua aplicabilidade ainda não se verifica. Dessa forma, o reconhecimento da importância de ter mais porta-vozes nas comunidades que façam de forma mais qualificada e autônoma a interlocução entre as entidades, instituições do Estado e as comunidades para a execução de seus direitos nos levou a propor o Projeto de Formação de Lideranças quilombolas para o Controle Social.

As reuniões de planejamento das etapas de formação em controle social puderam orientar as ações dos envolvidos em tal Projeto para estabelecer um diálogo entre aqueles que são alvos de Projeto e aqueles que elaboraram o mesmo, na tentativa de fugir daquilo que poderia ser interpretado como certa imposição do saber. O diálogo construído com as lideranças das comunidades envolvidas nesta Proposta permitiu dar crédito às opiniões das próprias lideranças para que as etapas de qualificação pudessem ser orientadas pelas demandas apresentadas pelas mesmas.

Nesse aspecto, com o objetivo de extrair das lideranças suas dúvidas, seus questionamentos e aquilo que gostariam de aprender, foi necessário transformar os conceitos de experiência distante em experiência próxima (Geertz, 1997) para aqueles que executariam as oficinas. Dessa forma, os saberes das lideranças e como contam suas lutas precisariam ser compreendidos para que a interlocução de saberes pudesse ser mais consistente.

Os dois exercícios eram desafiadores, e as oficinas sobre questões jurídicas foi o tema mais difícil de ser dialogado e permitiu que enxergássemos, na prática, como a construção do conhecimento acadêmico, sobretudo o conhecimento jurídico, se constitui de forma a dificultar o seu acesso aos "não iniciados".

Os diálogos estabelecidos entre aqueles responsáveis pela coordenação das oficinas e as lideranças quilombolas participantes do Projeto expressavam, de certa forma, um confronto entre dois campos semânticos distintos: o das lideranças quilombolas, inseridas em suas dinâmicas próprias de compreensão da realidade e o da academia através das suas estratégias de "socialização do saber".

A aproximação dos campos semânticos foi pretendida, a partir da compreensão que se conhece o mundo "do outro" por sobre os "seus ombros" (Geertz,1989). No nosso caso, numa relação dialética entre os saberes quilombolas e os saberes acadêmicos.

Embora tal diálogo não tenha se mostrado "fácil", pelas implicações já mencionadas, acreditamos que os quilombolas ao acessar saberes formais é (im)provável que estabeleçam estratégias específicas de exercer o controle social, e portanto, transcender de sua condição de alvos do direito, para sujeitos sociais que se organizam na busca e efetivação de tais direitos 
de forma mais autônoma.

Por sua vez, a academia ao experienciar essa prática pedagógica específica pôde redefinir suas bases metodológicas para a "pesquisa social", adotando uma postura implicada, ou seja, nos interstícios da observação-prática.

Diante dessa experiência observamos que os sujeitos de direitos, aqui os quilombolas, temse articulado em movimentos específicos e adotado várias estratégias para acessar o seu direito territorial, historicamente negado. Dentre as distintas estratégias, adotam além de ocupações de espaços públicos, marchas, romarias, greves de fome, a ocupação dos espaços acadêmicos. Nesse sentido, articularam com a Universidade Estadual do Maranhão o Projeto de Formação para Quilombola para o Controle Social que embora não tenha mudado a drástica realidade da negação da titulação dos territórios quilombolas, possibilitou a luta mais qualificada dos participantes para a conquista de tal direito.

Após cinco anos da realização desse processo formativo, temos observado uma maior autonomia das lideranças, no sentido de que suas mobilizações e interlocução com o poder público têm sido exercidas pelos próprios quilombolas. Algumas das lideranças partícipes do Projeto engajaram-se em frentes de lutas, a partir de vários canais estratégicos, dentre os quais o político partidário, sobretudo de orientação progressista e democrática.

Não podemos precisar a mudança nas estruturas cerceadoras da conquista do direito territorial quilombola. Por outro lado, cabe aportar que dentre as análises possíveis, à luz da ecologia política, inferir que acessar determinados códigos da sociedade hegemônica, também se expressa como resistência à conflitualidade estruturante.

\section{REFERÊNCIAS}

ALMEIDA, Alfredo Wagner Berno de. Terras de quilombo, terras indígenas, "babaçuais livres", "castanhais do povo", faxinais e fundos de pasto: terras tradicionalmente ocupadas. Manaus: PGSCA-UFAM, 2008

Identificação das comunidades remanescentes de quilombo em Alcântara/MA. São Luis: mimeo. 2002 (Laudo Antropológico. Vol. I)

ANDRADE, Maristela de Paula. Novos Sujeitos de Direitos seus Mediadores: uma reflexão sobre processos de mediação. Antropolítica: Revista Contemporânea de Antropolítica. N. 27 , 2009.

ASSUNÇÃO, Matthias Röhrig. "Quilombos maranhenses." In: Liberdade por um fio: história dos quilombos no Brasil. São Paulo: Companhia das Letras, 1996, p. 436.

BOURDIEU, Pierre. O Poder Simbólico. $7^{\mathrm{a}}$ ed. Rio de Janeiro: Bertrand Brasil, 2004.

CALVI, Kéttini Upp. O Controle Social nos Conselhos de Políticas e de Direitos. Emancipação. v. 8, n. 1, 2008.

FURTADO, Marivania Leonor Souza, Aquilombamento contemporâneo no Maranhão: um Rio Grande de possibilidades e suas barragens. São Luis: EdUEMA.2018

GEERTZ, Cliford. A interpretação das culturas. Rio de Janeiro. LTC -Livros Técnicos e Científicos Editora S.A. 1989

Vozes, 1997

O saber local: novos ensaios em antropologia interpretativa. Petrópolis - RJ. Ed.

GILROY, Paul. O Atlântico negro: modernidade e dupla consciência. $34^{\circ}$ Edição. Rio de Janeiro: Universidade Candido Mendes, Centro de Estudos Afro-Asiáticos, 2001 
KOLLODY, Andressa; LUÍZ, Danuta Estrufika Cantoia. Controle social: entre a contradição e a complementaridade. Rev. Londrina, V. 16, N.2, P. 142-165, JAN./JUN. 2014.

LEFF, Enrique. Racionalidade Ambiental: a reapropriação social da natureza. Trad. Luís Carlos Cabral. Rio de Janeiro: Civilização Brasileira, 2006.

MALDONADO-TORRES, Nelson. Sobre la colonialidad del ser: contribuciones al desarrollo de un concepto. IN. CASTRO-GÓMEZ, Santiago; GROSFOGUEL, Ramón. (Org.) E1 giro decolonial: reflexiones para una diversidad epistémica más allá del capitalismo. Bogotá: Siglo del Hombre Editores; Universidad Central, Instituto de Estudios Sociales Contemporáneos y Pontificia Universidad Javeriana, Instituto Pensar, 2007. p.127-167

MIGNOLO, Walter D. Os esplendores e as misérias da "ciência": colonialidade, geopolítica do conhecimento e pluri-versalidade epistémica. IN. SANTOS. Boaventura de Sousa (Org). Conhecimento prudente para uma vida decente: um discurso sobre as ciências revisitado. São Paulo: Cortez, 2006. p 667-709

MUNIZ, Sérgio César Correa Soares. Da mediação à territorialização: o caso da "Área Comunitária” em Pedro do Rosário - MA. Monografia do Curso de Ciências, Universidade Estadual do Maranhão. São Luís, 2014

SANTOS, Boaventura de Sousa. A construção multicultural da igualdade e da diferença. Rio de Janeiro: 1989, mimeo.

SCHERER-WARREN, Ilse. Redes de movimentos sociais na América Latina - caminhos para uma política emancipatória? Cad. CRH, Salvador. Vol. 21 no. 54, 2008.

SILVA, Maria Aparecida de Moraes. A luta pela terra: experiência e memória. Coleção Paradidáticos. Série Poder. São Paulo: Fundação Editora da UNESP, 2004. 